\title{
Modelo experimental do carcinossarcoma 256 de Walker em bexiga de ratos $^{1}$
}

\author{
Experimental model of Walker 256 carcinosarcoma in rats bladder
}

\author{
Conceição Aparecida Dornelas ${ }^{2}$, Paulo Roberto Carvalho de Almeida ${ }^{3}$, Germana Lopes do Nascimento ${ }^{4}$, Érika Bastos \\ Lima $^{4}$, Manoel Odorico de Moraes 5 \\ 1. Trabalho realizado no laboratório de Oncologia Experimental do Departamento de Fisiologia e Farmacologia da Faculdade de Medicina \\ da Universidade Federal do Ceará (UFC). \\ 2. Mestre em Urologia pela Universidade Estadual do Rio de Janeiro, aluna do Doutorado em Cirurgia (UFC). \\ 3. Prof. Adjunto Patologia da UFC. \\ 4. Acadêmicas de Medicina da UFC. \\ 5. PhD. Prof. Adjunto de Farmacologia Clínica e Prof. Adjunto de Oncologia da UFC.
}

\section{RESUMO}

Objetivo: Estudar um modelo animal para tumor de bexiga com Walker 256. Métodos: Bexigas de ratos Wistar foram cateterizadas via uretral e lesão de parede vesical foi realizada por compressão extrínsica, com pequena pinça, após laparotomia. A seguir 0,3 ml de suspensão contendo $3 \times 10^{5}$ células viáveis de carcinossarcoma de Walker foram instiladas em cada bexiga. Os animais foram sacrificados após oito e 13 dias. Resultados: O índice de pega do tumor foi de 100\%. A média de sobrevida foi de 14,5 dias. Conclusão: O modelo estudado foi eficiente e poderá levar subsídios para o estudo experimental em tratamentos de carcinomas de bexiga localmente invasivos em ratos.

Descritores: Neoplasias da Bexiga. Carcinoma 256 de Walker. Ratos.

\section{ABSTRACT}

Purpose: An animal model to study bladder tumor with Walker 256. Methods: Bladders rats Wistar was catheterized via urethra and compression lesion of the wall bladder was realized with a little clamping after laparotomy. One total of the 0,3 ml suspension with $3 \times 10^{5}$ cels viable of the carcinossarcoma was instilled into each bladder. The animals were sacrificed after eight and 13 days. Results: The index of tumor incidence was $100 \%$ and the average of surviving was 14,5 days. Conclusion: The model estudied was efficient and will can to take subsidy the study experiemental in treatment of local invasise bladder cancer.

Key words: Bladder Neoplasms. Carcinosarcoma 256, Walker. Rats.

\section{Introdução}

O carcinossarcoma 256 de Walker era um carcinoma quando surgiu espontaneamente na glândula mamária de ratos fêmeas albinos prenhes. Recebeu esse nome em homenagem ao professor George Walker ${ }^{1}$ que iniciou o seu estudo em 1928. Desde então ele vem sendo mantido em diversos laboratórios no mundo inteiro como um recurso valioso no auxílio à pesquisa básica em oncologia. São numerosos os trabalhos sobre o tumor de Walker, seu comportamento biológico, suas alterações bioquímicas e efeitos metabólicos ${ }^{2,3}$, e sua utilização em modelos experimentais no pulmão ${ }^{4}$, estômago ${ }^{5}, \operatorname{rim}^{6}$, cavidade oral $^{7} \mathrm{e}$ fígado ${ }^{8}$. Nosso objetivo é o estudo de um modelo experimental para Walker em bexiga.

\section{Métodos}

Foram ao todo 39 ratos fêmeas Wistar com peso entre 180 e 200 gramas, provenientes do Biotério Central da Universidade Federal do Ceará. A manutenção do carcinossarcoma 256 de Walker foi realizada através de inoculação intramuscular de suspensão de células tumorais, em face medial de coxa, com repicagem a cada oito dias. Durante o processo de inoculação para manutenção parte da suspensão foi utilizada para o nosso experimento. Essa suspensão foi avaliada em sua quantidade e viabilidade celular sob câmara de Neubauer ao microscópio corada com azul de trypan. Vinte e nove ratos fêmeas foram anestesiadas com Thiopental sódico (Thionembutal - Abbot), na dose de $4 \mathrm{mg} / 100$ gramas de peso corporal como recomendado por Griffith $^{9}$. Após tricotomia e antissepsia com polvidine (polivinilpirrolidona), os animais foram submetidos à incisão abdominal supra púbica longitudinal mediana de $1 \mathrm{~cm}$ de extensão para exposição da bexiga e a seguir submetidas a cateterização uretral, após antissepsia, com cateter de polietileno Angiocat $24 \mathrm{BD}$, sem agulha, a olho nu, com cuidado, levando em consideração o trajeto uretral paralelo ao canal vaginal, fazendo uma angulação cefálica a $6 \mathrm{~mm}$ do meato. Ao penetrar na bexiga a confirmação da posição ocorreu com a imediata eliminação espontânea de gotas de urina pelo cateter. Este então foi fixado com fita crepe, sendo aguardado o completo esvaziamento da bexiga. A seguir foi realizado um pinçamento da parede da bexiga anteriormente 
exposta com uma pinça hemostática infantil, delicadamente sem fechar a cremalheira e com cuidado para não perfurar a bexiga, apenas com objetivo de lesar (por compressão) a parede em suas camadas mais internas. Dando prosseguimento ao procedimento, através do cateter uretral foram inoculados $3 \times 10^{5}$ células de carcinossarcoma de Walker, comprimindo o meato uretral com pequeno grampo de plástico para evitar a eliminação prematura do conteúdo por cerca de 60 minutos. A parede abdominal foi então fechada por planos com chuleio simples. Os animais póscirurgia receberam limpeza dos pelos de resíduos sanguíneos sendo colocados em gaiolas 3 a 3 com alimento, ração e água ad libitum, mantidos a uma temperatura em torno dos $24^{\circ} \mathrm{C}$ sob luz ambiente. Cinco animais foram sacrificados ao final de oito dias. Quatro animais foram sacrificados ao final de 13 dias. Vinte animais foram deixados para observação da sobrevida. Foram realizados dois grupos controles. No primeiro grupo controle, com cinco animais após anestesia foi submetido à laparotomia e lesão vesical com pinça, porém sem a inoculação de suspensão de células do tumor de Walker, com sacrifício após o término da lesão. O segundo grupo controle, também com cinco animais, após anestesia foi submetido cateterização uretral e inoculação transcateter $3 \times 10^{5}$ células de tumor de Walker, mantendo compressão uretral por 180 minutos. Estes animais foram sacrificados ao final de oito dias.

\section{Resultados}

O Índice de pega foi de $100 \%$ dos casos.

Os animais sacrificados no oitavo dia encontravam se bem clinicamente. Ao exame macroscópico em necrópsia, não mostraram comprometimento visceral exceto em bexiga que apresentava umbilicação de sua parede em região endurecida à palpação (Figura 1), formando uma retração para o interior de sua luz vesical.

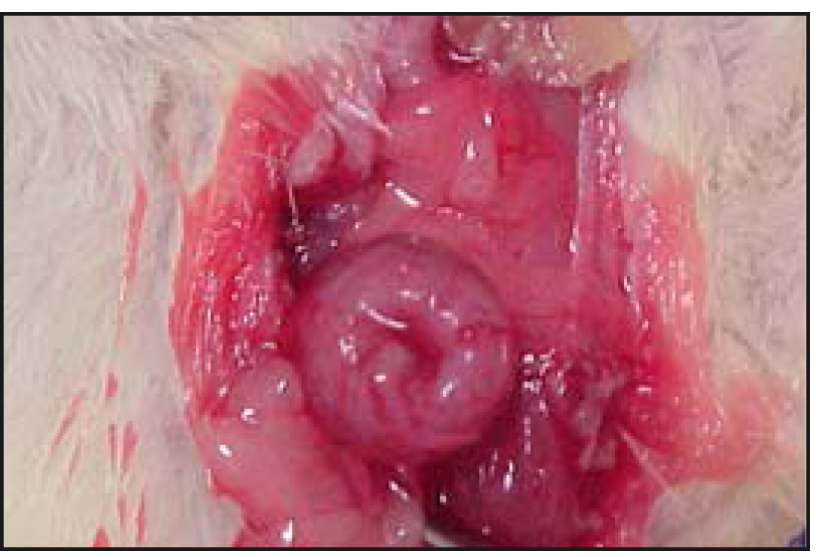

FIGURA 1 - Umbilicação em bexiga.

Os ureteres e rins observados ao microscópio cirúrgico estavam livres de tumorações e compressões. Na abertura da bexiga o tumor se apresentava amarelo pálido, crescendo apenas no sítio da lesão realizada com o pinçamento, crescendo de forma exofítica, endurecido para pétreo, superfície regular arredondada medindo no seu maior diâmetro em média 5,4 mm, sem ulcerações que aos cortes se assemelhava a um leque invadindo toda a parede vesical (Figura 2). Em um dos animais foi observado um pequeno cálculo vesical, medindo $3 \mathrm{~mm}$ de diâmetro de cor branca e facilmente fragmentado (Figura 3).

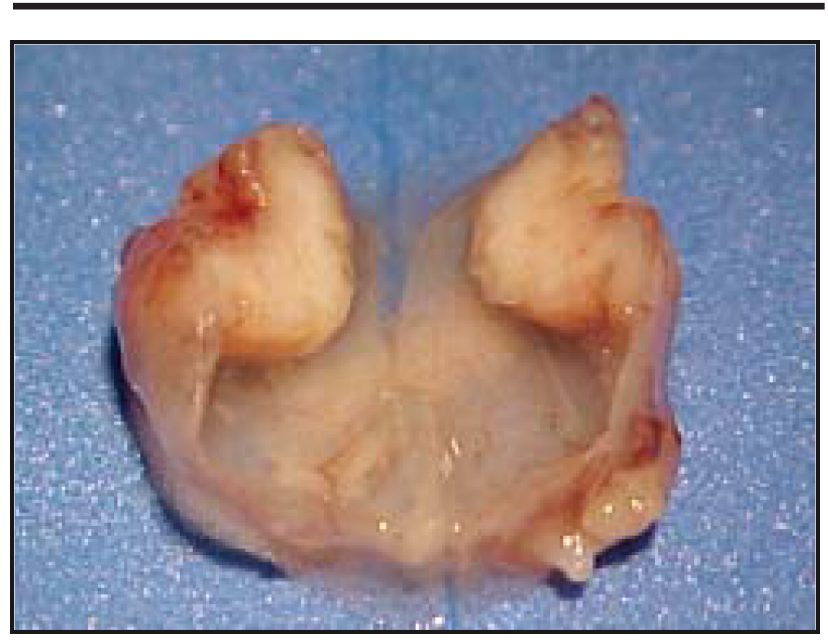

FIGURA 2 - Tumoração em bexiga aberta.

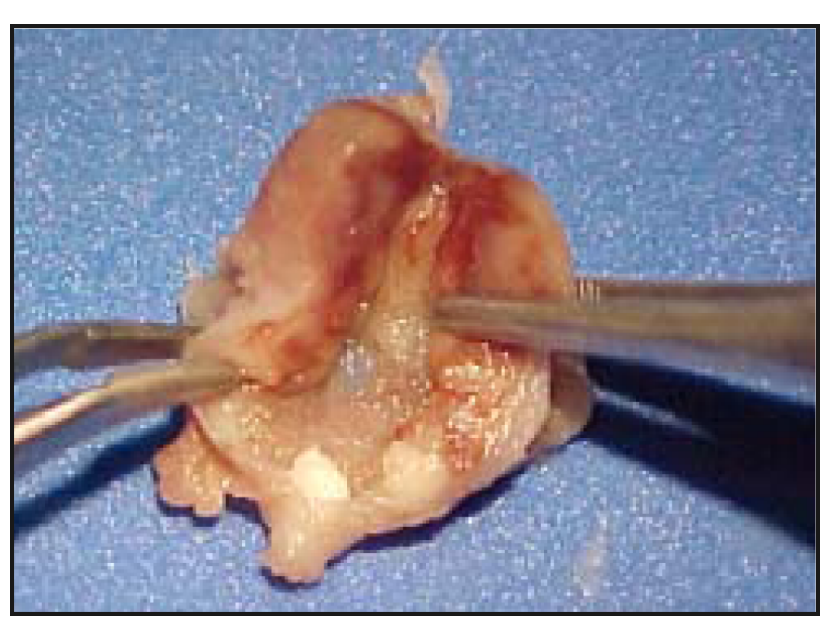

FIGURA 3 - Cálculo em bexiga aberta com tumor de parede.

O estudo histológico das bexigas dos 5 animais sacrificados mostrou um carcinossarcoma constituído basicamente de dois padrões celulares, um deles de células poligonais e o outro de células fusiformes com hipercromasia, polimorfismo nuclear e mitoses atípicas. A neoplasia invadia a submucosa preservando, contudo a membrana basal e o epitélio suprajacente, da mucosa, e infiltrava toda a espessura da parede, através da muscular até a serosa. Estudo radiológico com uretrocistografia realizado no $10^{\circ}$ dia de inoculação mostra falha de enchimento afunilada na cúpula vesical (Figura 4). Na Figura 5 , cortes da bexiga mostram a massa tumoral invadindo a cúpula vesical, o afunilamento visto da luz e finalmente a luz vesical livre correspondendo à imagem radiológica. $\mathrm{Na}$ Figura 6 a imagem da cúpula vesical encontra-se livre. Os animais sacrificados no $13^{\circ}$ dia evoluíram clinicamente com hematúria macroscópica. A necrópsia mostrou bexiga completamente invadida pela tumoração da cúpula até o colo vesical invadindo toda a parede, tornando o órgão rígido e pétreo deixando pequena a luz vesical. 


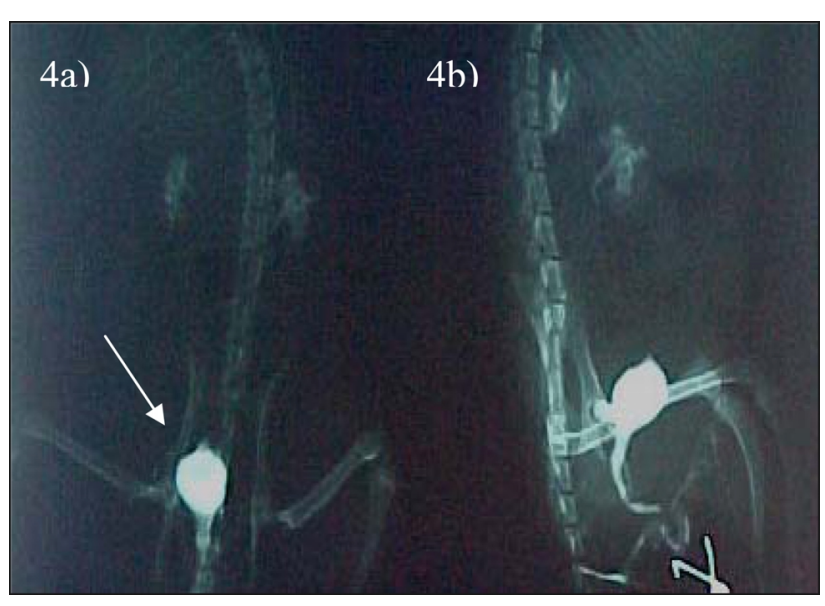

FIGURA 4 - Uretrocistrografia. a)AP e b)Perfil cúpula vesical apresenta falha de enchimento com afunilamento (seta).

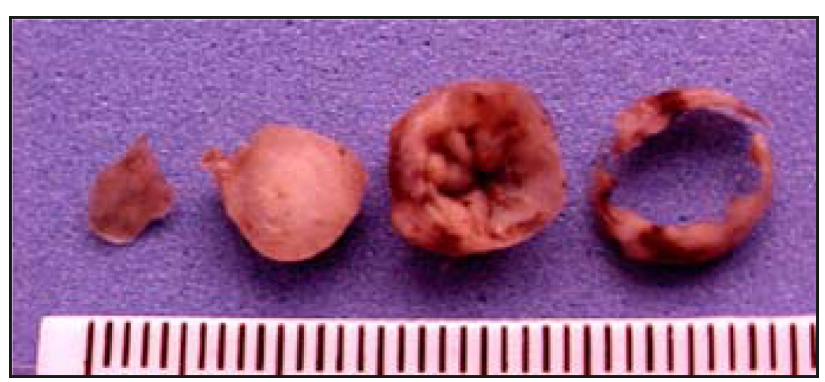

FIGURA 5 - Cortes transversais de parede de bexiga mostrando massa sólida em cúpula vesical afunilada. Escala em mm.

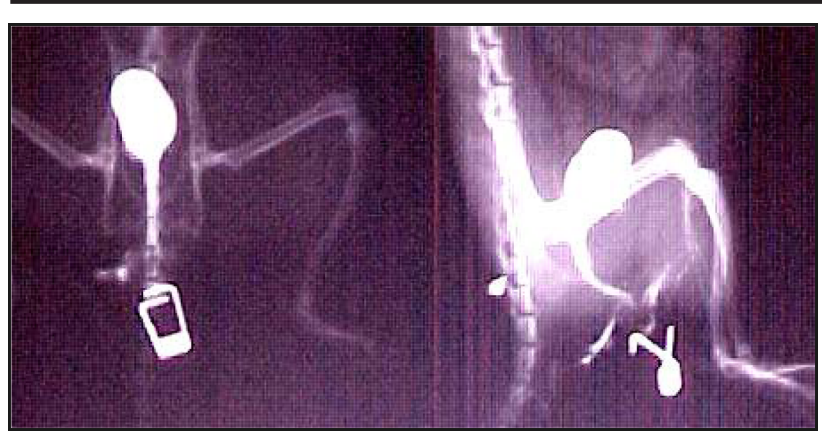

FIGURA 6 - Uretrocistografia cúpula vesical livre

Os 20 animais que foram destinados ao estudo da sobrevida evoluíram clinicamente com hematúria, diminuição da movimentação, tornando-se inicialmente irritadiços emitindo guinchos ao serem manipulados e posteriormente apáticos com perda progressiva de peso, interrompendo a ingestão de alimentos e água, evoluindo para o óbito rapidamente entre 24 e 48 horas. Todos foram submetidos à necropsia. A inspeção de cavidade abdominal mostrou em todos os ratos a partir do $14^{\circ}$ dia de inoculação, invasão tumoral por contigüidade da parede da bexiga invadindo útero e adjacências, alguns deles alças intestinais e carcinomatose peritonial com líquido ascítico hemorrágico. Fígado e baço encontravam se livres. A inspeção da cavidade torácica mostrou pulmões róseos sem nódulos, sem hemorragias, sem líquido pleural. Em cinco animais observamos rins unilateralmente aumentados de tamanho com nodulações em sua superfície. A média da sobrevida dos animais foi de 14,5 dias (mínimo 12 - máximo 17 dias), a mediana de 14,5 dias nas freqüências de $(12-1 ; 13-2 ; 14-$ $1 ; 15$ - 7; 16 - 5; 17 - 4). O desvio padrão foi de 2,91. O estudo histológico do primeiro grupo controle apenas com lesão sem a inoculação de células de Walker mostrou solução de continuidade entre mucosa e muscular no local do pinçamento. $\mathrm{O}$ segundo grupo controle foi submetido à necrópsia, a qual não evidenciou qualquer implante tumoral em bexiga ou órgãos abdominais.

\section{Discussão}

Na revisão bibliográfica realizada não foi encontrado trabalho experimental utilizando tumor de Walker $256 \mathrm{em}$ bexiga, portanto, não podemos comparar seu comportamento biológico. Entretanto, quando comparado com os índices de sucesso de implantes desde a sua descoberta em 1928 até os dias atuais temos uma evolução deste índice de $56 \%$ para $100 \%$, quando injetados por via muscular bem como nos diversos modelos experimentais para tumores de Walker em pulmão, estômago, rim, cavidade oral e fígado. ${ }^{4,5,6,7 \mathrm{e} 8}$. Há de se levar em conta a indiferenciação sofrida pelo tumor de Walker para um carcinossarcoma, tipo histológico mais agressivo, o que deve ter corroborado para o aumento do índice de pega. A quantidade de células para o modelo em bexiga provém da orientação de Moraes SP e col. ${ }^{10}$, que após sucesso em inoculação de $3 \times 10^{5}$ células ascítica viáveis de Walker 256 em flanco de ratos Wistar, não conseguiram implante com a inoculação de $2 \times 10^{5}$ células. Optamos então por iniciar com o mínimo necessário, mesmo considerando a possibilidade de diversidade de comportamento biológico do tumor em diferentes centros de pesquisa bem como o maior risco da eliminação do conteúdo de células pelo fluxo de urina, que poderia resultar um alto índice de insucesso. Também nos baseamos nos trabalhos de Borda e col. ${ }^{11}$, que relatam a inoculação em bexiga de $2,5 \times 10^{4}$ de suspensão de células de Carcinoma de Células Transicionais (CCT) bem como de Chin e $\mathrm{col}^{12}$, que inoculando de $5 \times 10^{5}$ células de CCT acrescentou o recurso de compressão da luz uretral por 30 minutos. A rotina de manutenção do Walker 256 retirando tumor sólido, fragmentando e coando, nos preocupava quanto a possível inoculação de um fragmento que resultasse em formação de um corpo estranho seguindo-se da formação de cálculos vesicais. Apenas um rato desenvolveu litíase. Calcificação de um coágulo antigo não eliminado oriundo da lesão de parede vesical? O tumor de Walker vesical, em nosso experimento invadiu a parede vesical e órgãos contíguos evoluindo com carcinomatose peritonial sem atingir fígado, baço e cavidade torácica, apresentando invasão do parênquima renal unilateral em 5 animais, sem contigüidade com órgãos vizinhos e sem comprometimento ureteral, com uma sobrevida média de 14,5 dias. Este comportamento biológico foi de maior agressividade apressando a morte do animal, comparando com as observações de Villas Boas e col. ${ }^{13}$, cuja média de sobrevida de ratos Wistar com implante tumoral em pata posterior (quantidade de células não discriminada), foi de 19 dias apesar de apresentarem metástase no fígado e pulmão. Há de se considerar a 
diferença entre as linhagens estudas e o tempo de manutenção do tumor em laboratório, que no referido estudo data de 1988. A sobrevida atual de ratos Wistar inoculados com tumor de Walker no laboratório de Oncologia Experimental da Universidade Federal do Ceará encontrase em torno de 13 dias quando se faz o inóculo no músculo na pata posterior ( $10^{6}$ células $), 14$ dias em rim direito 6 ( $3 \mathrm{x}$ $10^{5}$ células $), 10$ dias no pulmão ${ }^{4}\left(5 \times 10^{5}\right.$ células $), 13$ dias no estômago ${ }^{5}\left(10^{6}\right.$ células) e 10 dias no fígado ${ }^{8}$ ( $3 \times 10^{5}$ células). No primeiro grupo controle ficou evidente que a lesão provocada com a pinça, é uma lesão que atinge a mucosa e a muscular profunda. Isso significa que o modelo é de um tumor localmente invasivo. Estudando o segundo grupo controle, confirmamos o já observado por Oliveira e col. ${ }^{5}$, que trabalhando com um modelo de estômago inoculando $10^{6}$ células de tumor de Walker não conseguiram o implante do tumor sem lesão na mucosa de estômago. Ou seja, também para o modelo em bexiga foi necessário solução de continuidade da mucosa. Nossas observações vêm de encontro aos estudos de Kikuchi e col. ${ }^{14}$ que obtiveram 92\% de implante de tumor de bexiga de rato (linhagem epitelial) utilizando $2 \times 10^{6}$ em 1001 de salina de fosfato tamponado mantendo compressão de uretra por 180 minutos sem lesão prévia. Células de tumores mesenquimais em ratos necessitam de solução de continuidade do epitélio vesical, ou será necessário aumentar o número de células para obtenção do implante vesical? É importante lembrar que $95 \%$ a $99 \%$ dos tumores de bexiga são tumores epiteliais sendo $90 \%$ deles CCT. Aproximadamente de $1 \%$ a $5 \%$ são de linhagem não epitelial. Nos Estados Unidos aproximadamente $60 \%$ de todo novo caso diagnosticado de câncer de bexiga é um carcinoma de células trancisionais bem diferenciado ou moderadamente diferenciado superficial, ou seja, confinado a lâmina própria ${ }^{15}$. O CCT de bexiga é uma doença multifocal e diferentes conceitos vêm tentando explicar este fenômeno de extraordinária importância clínica, principalmente no que se refere à recorrência de 40 a $80 \%$ da doença em dois anos após tratamentos convencionais. Estudos citogenéticos têm levado a conclusão de que tumores sincrônicos ou metacrônicos de bexiga são derivados de focos de micrometástases que migrariam do sítio de origem (teoria monoclonal). Em posição oposta estão aqueles que após estudo de alterações morfológicas e mapeamento histoquímico em áreas adjacentes aos sítios tumorais, defendem a teoria policlonal ${ }^{16}$. Takahashi e $\mathrm{col}^{17}$ mostraram evidencias de que a maioria dos tumores de bexiga é monoclonal e pequena porcentagem é policlonal. Em que pese a crítica aos modelos experimentais que utilizam a inoculação de células, de que não passam de "estudo de metástase" (uma fase apenas da carcinogênese), baseados na teoria monoclonal do tumor de bexiga, que vem sendo defendida pelos estudos citogenéticos, nos parece adequado no momento, o caminho desta metodologia pelo menos como uma fase experimental para testes terapêuticos.

\section{Conclusão}

O modelo de lesão por compressão extrínseca de parede da bexiga foi uma técnica eficiente para implante do tumor de Walker (100\%), tornando-se mais um instrumento para estudo e análise de seu comportamento biológico bem como de suas alterações metabólicas. O modelo estudado, inoculando células de CCT, abre uma nova possibilidade para estudo experimental terapêutico de tumores de bexiga localmente avançados.

\section{Referências}

1. Earle, WR A study of the Walker rat mammary carcinoma 256 in vivo and in vitro. Am J Cancer. 1935; 8:566-612.

2. VidoAA, Cavalcanti TC, Guimarães F, Vieira-Matos NA, Retorri O. The hemolytic component of câncer erythrocytes of rats bearing multifocal inoculations of the Walker 256 tumor. Braz J Med Biol Res 2000; 33(7):815-22.

3. Guimarães F, Rettori O, Vieira-Matos NA, Fernandes GA. The influence of septal lesions on sodium and water retention induced by Walker 256 tumor. Braz J Med Biol Res 1999; 32(3):309-17.

4. Gomes-Neto A, Pessoa BBGP, Aguiar AS, Furtado BM, Moraes MO, Ribeiro RA. Modelo de tumor de pulmão em rato com o carcinossarcoma de Walker. Acta Cir Bras. 2002; 17(1):12-22. Disponível em URL: http://www.scielo.br/acb

5. Oliveira PFM, Henriques IA, Rodrigues-Filho F, Almeida PRC \& Moraes, MO. Estabelecimento de um modelo de tumor experimental pela inoculação do tumor de Walker em estômago de rato. Acta Cir Bras. 1998; 13(4):243-8. Disponível em URL: http://www.scielo.br/acb

6. Silva LFG, Soares FSD, Anselmo JNN, Fé DMM, Cavalcante JLBG, Moraes MO, Vasconcelos PRL. Modelo de tumor experimental em rim de ratos. Acta Cir Bras. 2002; 17(1):62-6. Disponível em URL: http://www.scielo.br/acb

7. Alves, APNN, Guedes RC, Costa-Lotufo LV, Moraes MEA, Pessoa CO, Ferreira FVA, Moraes MO. Modelo experimental de tumor na cavidade oral de ratos com carcinossarcoma de Walker 256. Acta Cir Bras. 2004; 19(4):354-60. Disponível em URL: http://www.scielo.br/acb

8. Zarur JM, Barreto MSF, Diógenes CA, Nascimento GL, Moraes MO. Quimioembolização transarterial hepática: modelo experimental de tumor em ratos. Acta Cir Bras. 2004; 19(5) 511-6. Disponível em URL: http://www.scielo.br/acb

9. Griffith JQ, Farris EJ. The rat laboratory investigation. New York: JB Lippincott; 1942.

10. Moraes SP, Cunha A, Rei Neto JA, Barbosa H, Roncollatto CAP, Duarte RF. Modelo experimental de tumor de Walker. Acta Cir Bras. 2000; 15(4):237-42. Disponível em URL: http://www.scielo.br/acb

11. Borda AP, Galan ML Santos AF, Gonzáles LL, Segoviano, PF, Sanchez AB. Algunos detalles em la puesta a punto de um modelo animal de tumor vesical. Actas Urol Esp. 1999; 23(9):740-9.

12. Chin J, Kadhim S, Garcia B, Kim YS, Karlik S. Magnetic Resonance Imaging for detecting and treatment monitoring of orthotopic murine bladder tumor implants. J Urol. 1991; 145:1297-301.

13. Villas-Boas FIP, Monico MH, Takehara CM. A sobrevida de ratos com tumor de Walker. Rev Odontol Univ Est São Paulo. 1988; 17(1/2):165-8. 
14. Kikuchi E. Xu SO, Hori M, Matei C. Detection and quantitative analysis of early state orthotopic murine bladder tumor using in vivo magnetic ressonance imaging. J Urol. 2003; 170:1375-8.

15. Messing EM. Urothelial tumors of the urinary tract.In Walsh C. Campbell's urology. 8ed. Philadelphia: Saunders; 2002. p.2732-84.

16. Simon R, Eltze E, Shafer KL Burger H. Cytogenetic analysis of multifocal bladder supports a monoclonal origin and intraepithelial spread of tumor cells. Cancer Res. 2001; 61:355-62.
17. Takahashi T, Habuchi T, Kakehi Y. Clonal and chronological genetic analyses of multifocal cancer of the bladder and upper urinary tract. Cancer Res. 1998; 58:5835-42.

\section{Agradecimentos}

Ao Prof. Manoel Odorico de Moraes nosso grande mestre e orientador da UFC.

\section{Correspondência:}

Prof. Dr. Manoel Odorico de Moraes

Universidade Federal do Ceará

Departamento de Fisiologia e Farmacologia

Rua Coronel Nunes de Mello, 1127

60340 Fortaleza-CE

Odorico@ufc.br
Conflito de interesse: nenhum Fonte de financiamento: nenhuma

Recebimento: 14/09/2005

Revisão: 19/10/2005

Aprovação: 09/11/2005

\section{Como citar este artigo:}

Dornelas CA, Almeida PRC, Nascimento GL, Lima EB, Moraes MO. Modelo experimental do carcinossarcoma 256 de Walker em bexiga de ratos. Acta Cir Bras. [periódico na Internet] 2006 Jan-Fev;21(1). Disponível em URL: http://www.scielo.br/acb

*Figuras coloridas disponíveis em $\underline{\text { http://www.scielo.br/acb }}$

\section{RECOMENDAÇÕES AOS AUTORES}

Os DESCRITORES/KEY WORDS são essenciais para a acessibilidade e recuperação dos artigos.

O DeCS (Descritores em Ciências da Saúde) facilita o acesso à informação e guia os usuários na localização e seleção da informação científica.

Incluir termos, nos descritores, que não estão no DeCS impedem a localização do artigo.

Portanto, se os autores desejarem que seu artigos sejam encontrados torna-se imperioso pesquisar no DeCS os termos corretos: acessar www.bireme.br e clicar em Terminologia em Saúde. A seguir Consulta ao DeCS e por fim Consulta por Palavra, nos idiomas inglês, espanhol e português. 